\title{
URBANEK, Peter, Wappen und Siegel Regensburger Bürger und Bürgerinnen im Mittelalter (bis 1486)
}

\author{
Isabelle Guerreau
}

\section{OpenEdition}

\section{Journals}

Édition électronique

URL : http://journals.openedition.org/ifha/953

DOI : $10.4000 /$ ifha. 953

ISSN : 2198-8943

Éditeur

IFRA - Institut franco-allemand (sciences historiques et sociales)

Référence électronique

Isabelle Guerreau, «URBANEK, Peter, Wappen und Siegel Regensburger Bürger und Bürgerinnen im Mittelalter (bis 1486) », Revue de l'IFHA [En ligne], Date de recension, mis en ligne le 01 janvier 2004 consulté le 22 septembre 2020. URL : http://journals.openedition.org/ifha/953 ; DOI : https://doi.org/ 10.4000/ifha.953

Ce document a été généré automatiquement le 22 septembre 2020.

(C)IFHA 


\title{
URBANEK, Peter, Wappen und Siegel Regensburger Bürger und Bürgerinnen im Mittelalter (bis 1486)
}

\author{
Isabelle Guerreau
}

La parution d'un nouvel ouvrage de sphragistique et d'héraldique est toujours un petit événement, surtout si l'on considère le décalage entre le nombre réduit de catalogues et l'importance quantitative de cette source essentielle que sont les sceaux pour l'héraldique et pour l'étude des représentations sociales, bien que l'on observe dans la dernière décennie un regain d'intérêt pour ces objets (publications de Eva Neukirch, Volker Steck, Robert Steiner, Andrea Stieldorf ou Wolfhard Vahl). Cet ouvrage est d'autant plus précieux que l'étude est consacrée à un groupe social qui, contrairement à l'aristocratie par exemple, n'a jusqu'à présent suscité que peu d'attention, celui des bourgeois, en l'occurrence de la ville de Ratisbonne.

Fruit d'une thèse achevée en 1988 et jusqu'alors uniquement consultable sur microfiches et sans images, cette publication a le considérable avantage de présenter un gros catalogue comprenant 1715 reproductions, dont 1543 photos de sceaux (en noir et blanc). Le catalogue est constitué de deux parties ; l'auteur a opté pour une présentation séparée des hommes et des femmes, provenant le plus souvent des mêmes familles - le choix de l'ordre alphabétique d'après le nom de famille rend toutefois les rapprochements faciles. La description des armoiries puis celle du sceau (forme, taille, légende - très simplifiée - et champ), à côté de la photographie, ainsi que les références des empreintes conservées forment un outil de travail clair et facile à manier. L'index des représentations héraldiques renvoyant aux diverses familles de Ratisbonne offre une aide supplémentaire à l'identification des armoiries, élément fort utile qui manque dans la majorité des catalogues de ce type.

Ce corpus est accompagné d'une analyse concise (une quarantaine de pages), mais qui esquisse clairement la progression de la pratique du scellage en fonction de la position des sigillants - notables (Vollbürger) ou simples bourgeois (Minderbürger), maîtres de métiers et représentants de la justice (Schultheiß) ou femmes - tout en insérant cette 
pratique dans le contexte social et en faisant ainsi apparaitre les enjeux liés au scellage. Dans un deuxième temps, l'auteur se penche sur l'utilisation et les types d'armoiries et de sceaux. L'on regrettera seulement l'absence d'analyse des légendes de sceaux. L'on notera enfin la tentative intéressante, présentée dans le dernier chapitre, pour déchiffrer sur les sceaux le codage des couleurs héraldiques figurées à l'aide de divers types de hachures. Tout comme l'auteur, on espère que cette publication incitera à des recherches de ce type sur d'autres villes, afin de pouvoir tirer des conclusions plus générales et de mieux discerner les particularités des sceaux des bourgeois de Ratisbonne.

Isabelle GUERREAU (International Max Planck Research School, Göttingen) 